\title{
FAKTOR-FAKTOR YANG BERHUBUNGAN DENGAN PEMBERIAN VITAMIN A PADA BALITA DI WILAYAH KERJA PUSKESMAS KANDAI KOTA KENDARI
}

\author{
Puspita Adriani \\ Akbid Yayasan Pendidikan Konawe, Jl. DII Panjaitan No. 217 Kel. Tuoy Kec. Unaaha Kab. Konawe - Sulawesi Tenggara, \\ 082292673717 \\ E-mail : puspitaadriani@yahoo.co.id
}

\begin{abstract}
ABSTRAK
Vitamin A adalah zat gizi yang paling esensial untuk pemulihan kesehatan dan kelangsungan hidup. Kekurangan Vitamin $A$ akan meningkatkan kesakitan dan kematian, mudah terserang penyakit infeksi seperti diare, radang paru-paru, pneumonia, dan akhirnya kematian. Survey pengambilan data awal di Puskesmas Kandai Kota Kendari Tahun 2016 dari 1.504 balita, yang diberikan Vitamin A sebanyak 1.250 (83,11\%) dan tidak diberikan sebanyak 254 (16,89\%). Tahun 2017 dari 1.624 balita, yang diberikan Vitamin A sebanyak 1.520 (93,60\%) dan tidak diberikan sebanyak 104 (6,40\%). Hal ini menunjukkan bahwa cakupan Vitamin A di Puskesmas Kandai belum mencapai target $100 \%$. Jenis penelitian analitik kuantitatif dengan pendekatan cross sectional. Populasi adalah seluruh ibu balita yang berada di Wilayah Kerja Puskesmas Kandai Kota Kendari pada tahun 2018 yaitu sebanyak 1.714 orang. Sampel 30 orang, dengan teknik penarikan sampel secara accidental sampling. Hasil analisis bivariat, nilai $p(0,001)<\alpha(0,05)$ (pengetahuan), nilai $p(0,015)<\alpha(0,05)$ (pendidikan), nilai $p$ $(0,000)<\alpha(0,05)$ (pekerjaan). Kesimpulan ada hubungan yang signifikan antara pengetahuan, pendidikan dan pekerjaan dengan pemberian Vitamin A pada balita (6-59) bulan.
\end{abstract}

Kata Kunci : vitamin A; pengetahuan; pendidikan; pekerjaan

\section{FACTORS ARE RELATEDGMNG VTAMNAFOR INFANIS (6-59) MONIHS AT KANDAI HEALTHCENIER KENDAR QTY \\ ABSTRACT}

\begin{abstract}
Vitamin A is the most essential nutrient for health recovery and survival. Vitamin A deficiency will increase pain and death, susceptible to infectious diseases such as diarrhea, pneumonia, pneumonia, and death. The initial data survey was collected at Kandai Health Center Kendari City on 2016, there were 1,504, Vitamin A was already given to 1,250 (83,11\%) and there were $254(16,89 \%)$ were not given. In 2017 there were 1,624 toddlers, who were given Vitamin A as many as 1,520 (93.60\%) and not given 104 (6.40\%). This shows that the coverage of Vitamin A at Kandai Health Center has not reached $100 \%$ of the target. Quantitative analytical with cross sectional approach is applied for this research. The population was all mothers of children under five who are in the working area of Kendari City Kandai Health Center in 2018, who are 1,714 people. Samples were 30 people, with sampling techniques used accidental sampling. The results of the bivariate Analysis study, $p$ value $(0.001)<\alpha(0.05)$ (knowledge), $p$ value $(0.015)<\alpha(0.05)$ (education), $p$ value $(0,000)<\alpha(0.05)$ (occupation).cThe conclusion is that there is a significant relationship between knowledge, education and employment with the provision of Vitamin A in infants (6-59) months.
\end{abstract}

Keywords: vitamin A; knowledge; education; occupation 


\section{LATAR BELAKANG}

Vitamin A adalah zat gizi yang paling esensial untuk pemulihan kesehatan dan kelangsungan hidup. Kekurangan Vitamin A akan meningkatkan kesakitan dan kematian, mudah terserang penyakit infeksi seperti diare, radang paru-paru, pneumonia, dan akhirnya kematian. Akibat lain yang paling serius dari kekurangan Vitamin A adalah rabun senja yaitu bentuk lain dari xeropthalmia termasuk kerusakan kornea mata dan kebutaan (Almatsier, 2009).

Penelitian yang telah dilakukan Word Health Organization (WHO) menunjukkan dari 20 juta balita di Indonesia setengahnya menderita kekurangan Vitamin A. Sedangkan data dari WHO, Indonesia merupakan salah satu negara yang pemenuhan Vitamin A tergolong rendah (Kemenkes RI, 2016).

Masalah kurang Vitamin A sub klinis dibeberapa provinsi masih cukup memprihatinkan, karena $50 \%$ balita masih mempunyai status Vitamin A rendah. Kurangnya Vitamin A akan mengakibatkan penurunan daya tahan tubuh terhadap penyakit yang berpengaruh pada kelangsungan hidup anak. Penanggulangan masalah kurang Vitamin A saat ini bukan hanya untuk mencegah kebutaan, tetapi juga dikaitkan dengan upaya memacu pertumbuhan dan kesehatan anak guna menunjang penurunan angka kematian bayi dan balita yang berpotensi terhadap peningkatan produktifitas kerja orang dewasa (Kemenkes RI, 2016).

Angka Kematian Balita (AKABA) di Kabupaten/Kota dalam lima tahun terakhir masih relatif tinggi dengan rata di atas 10 kasus. Secara absolut angka tersebut relatif kecil, tapi bila diproporsikan dengan jumlah balita pada masing-masing Kabupaten tersebut, maka jumlah tersebut cukup signifikan (Dinkes Sultra, 2017).

Berdasarkan Profil Dinas Kesehatan Provinsi Sulawesi Tenggara diketahui bahwa cakupan pemberian Vitamin A cenderung mengalami peningkatan dalam lima tahun terakhir. Tahun 2012 sebesar 73,93\%, tahun 2013 sebesar 74,2\%, tahun 2014 sebesar
72,98\%, tahun 2015 sebesar 78,39\%, dan pada tahun 2016 menjadi sebesar 80,24\%. Penurunan hanya terjadi pada tahun 2014, hal ini disebabkan adanya penetapan sasaran program yang tidak konsisten khususnya sasaran balita dan menjadi penyebab dalam pencatatan/pelaporan yang kurang cermat, tidak ada atau masih rendahnya kegiatan sweeping Vitamin A, atau kurangnya sosialisasi tentang pemberian kapsul Vitamin A kepada masyarakat (Dinkes Sultra, 2017).

Program pemberian kapsul Vitamin A pada balita di Puskesmas Kandai dilaksanakan setiap tahunnya pada bulan Februari dan Agustus. Pada tahun 2015 dari 1.338 balita yang diberikan Vitamin A sebanyak 1.156 (86,40\%), dan yang tidak diberikan sebanyak 182 (13,60\%). Tahun 2016 dari 1.504 balita, yang diberikan Vitamin A sebanyak 1.250 $(83,11 \%)$ dan yang tidak diberikan sebanyak 254 (16,89\%). Tahun 2017 dari 1.624 balita, yang diberikan Vitamin A sebanyak 1.520 $(93,60 \%)$ dan yang tidak diberikan sebanyak 104 (6,40\%). Hal ini menunjukkan bahwa cakupan Vitamin A di Puskesmas Kandai belum mencapai target dimana target capaian Vitamin A 100 \% (Profil Puskesmas Kandai, 2018).

Meskipun di Puskesmas Kandai belum mencapai target 100\% tapi tidak menutup kemungkinan pada bulan atau tahun mendatang akan mengalami peningkatan. Untuk itu diperlukan upaya dan pendekatan untuk mencegah timbulnya penyakit-penyakit yang disebabkan oleh kurangnya Vitamin A seperti ISPA, infeksi saluran kemih dan saluran pencernaan serta terjadinya kelainan pada mata (rabun senja, daya pandang menurun dan katarak), serta untuk memperbaiki status Vitamin A bayi dan balita, yaitu yang pertama dengan memberikan Vitamin $A$ dosis tinggi pada wanita yang sedang menyusui. Pasokan Vitamin A diawal kehidupan akan tercukupi melalui Air Susu Ibu (ASI), jika ibu mempunyai status Vitamin A yang baik, dan yang kedua dapat memberikan satu dari beberapa dosis Vitamin A pada bayi dan balita (Kemenkes RI, 2016). 
Tercapai atau tidaknya pemberian Vitamin A pada balita dipengaruhi oleh beberapa faktor terutama faktor dari ibu diantaranya pengetahuan dan pendidikan terhadap pemberian Vitamin A pada balitanya, serta pekerjaan atau kesibukan ibu yang dapat menghambat ibu untuk membawa balita guna diberikan Vitamin A di Posyandu atau Puskesmas (Fatmawati dkk, 2010)

Berdasarkan hal tersebut penulis tertarik untuk melakukan penelitian yang bertujuan untuk mengetahui faktor-faktor yang berhubungan dengan pemberian Vitamin $A$ pada balita (6-59) Bulan.

\section{METODE}

Jenis penelitian ini adalah kuantitatif dengan pendekatan cross sectional. Populasi adalah seluruh ibu balita yang berada di Wilayah Kerja Puskesmas Kandai Kota Kendari pada tahun 2018 yaitu sebanyak 1.714 orang. Sampel 30 orang, dengan teknik penarikan sampel secara accidental sampling. Variabel yang diteliti dalam penelitian ini adalah variabel dependen (Vitamin A), dan variabel independen (pengetahuan, pendidikan, dan pekerjaan). Analisis penelitian menggunakan chi-square. Instrumen penelitian menggunakan kuesioner.

\section{HASIL}

Hasil analisis bivariat faktor-faktor yang berhubungan dengan pemberian Vitamin $\mathrm{A}$ pada balita (6-59) bulan di Wilayah Kerja Puskesmas Kandai Kota Kendari dapat dilihat dalam tabel 1 berikut ini :

Tabel 1. Hasil analisis bivariat faktor-faktor yang berhubungan dengan pemberian Vitamin A pada balita (6-59) bulan di Wilayah Kerja Puskesmas Kandai Kota Kendari

\begin{tabular}{|c|c|c|c|c|c|c|c|c|}
\hline \multirow[t]{3}{*}{$\begin{array}{l}\mathrm{N} \\
0\end{array}$} & \multirow[t]{3}{*}{$\begin{array}{c}\text { Variab } \\
\text { el }\end{array}$} & \multicolumn{4}{|c|}{$\begin{array}{l}\text { Pemberian Vitamin } \\
\text { A pada Balita (6- } \\
\text { 59) Bulan }\end{array}$} & \multirow{2}{*}{\multicolumn{2}{|c|}{ Jumlah }} & \multirow[t]{3}{*}{$\begin{array}{c}\text { p- } \\
\text { valu } \\
\mathbf{e}\end{array}$} \\
\hline & & \multicolumn{2}{|c|}{$\mathrm{Ya}$} & \multicolumn{2}{|c|}{ Tidak } & & & \\
\hline & & $\mathrm{n}$ & $\%$ & $n$ & $\%$ & $\mathrm{n}$ & $\%$ & \\
\hline \multicolumn{9}{|c|}{ Pengetahuan } \\
\hline 1 & Baik & $\begin{array}{l}1 \\
3\end{array}$ & $\begin{array}{l}43 \\
3\end{array}$ & 1 & 3,3 & 4 & 46,7 & \\
\hline 2 & Cukup & 6 & 20 & 2 & 6,7 & 8 & 26,7 & 0,00 \\
\hline
\end{tabular}

\begin{tabular}{lcccccccc}
\hline 3 & Kurang & 1 & 3,3 & 7 & 23, & 8 & 26,7 & 1 \\
& & & & 3 & & & \\
\hline \multicolumn{2}{l}{ Pendidikan } \\
1 & Tinggi & 1 & 53, & 3 & 10 & 1 & 63, & \\
& & 6 & 3 & & & 9 & 3 & \\
2 & Renda & 4 & 13, & 7 & 23, & 1 & 36, & 0,01 \\
& $h$ & & 3 & & 3 & 1 & 7 & 5 \\
\hline & Pekerjaan & & & & & & & \\
1 & Tidak & 1 & 53, & 1 & 3,3 & 1 & 56, & \\
& Bekerja & 6 & 3 & & & 7 & 7 & \\
2 & Bekerja & 4 & 13, & 9 & 30 & 1 & 43, & 0,00 \\
& & & 3 & & & 3 & 3 & 0 \\
\hline
\end{tabular}

Tabel 1 menunjukkan bahwa faktor pengetahuan, pendidikan dan pekerjaan dengan pemberian Vitamin A pada balita (6-59) bulan diperoleh nilai $p$-value lebih kecil dari alpha 0,05 yang berarti bahwa Ho ditolak dan Ha diterima, maka dapat disimpulkan bahwa ada hubungan yang signifikan antara pengetahuan, pendidikan dan pekerjaan dengan pemberian Vitamin A pada balita (6-59) bulan. Tempat penelitian di Wilayah Kerja Puskesmas Kandai Kota Kendari dan dilakasanakan pada bulan November Desember tahun 2018.

\section{PEMBAHASAN \\ Hubungan Pengetahuan dengan Pemberian Vitamin A pada Balita (6-59) Bulan}

Pengetahuan sangat dibutuhkan agar masyarakat dapat mengetahui mengapa mereka harus melakukan suatu tindakan sehingga perilaku masyarakat dapat lebih mudah untuk diubah kearah yang lebih baik.

Bart (2009) mengatakan bahwa perilaku yang dilakukan atas dasar pengetahuan akan lebih bertahan dari pada perilaku yang tidak didasari oleh pengetahuan. Pengetahuan yang dimiliki seseorang merupakan dasar untuk berbuat, karena itu kemampuan seseorang melakukan sesuatu tergantung pengetahuan yang ia miliki. Atas dasar pengetahuan tentang manfaat dan dampak akibat tidak diberikan Vitamin A maka memungkinkan ibu untuk hadir pada setiap pelaksanaan Posyandu.

Hasil penelitian ini sejalan dengan penelitian yang dilakukan oleh Cahyaningrum (2017) dengan judul "Hubungan Tingkat Pengetahuan Ibu tentang Vitamin A dengan 
Kepatuhan Memberikan Kapsul Vitamin A pada Balita Usia 12-59 Bulan di Wilayah Kerja Puskesmas Rowosari Kota Semarang" yang menyebutkan bahwa ibu yang memiliki pengetahuan baik akan mempermudah dan lebih memahami akan pentingnya kegiatan Posyandu pada balitanya. Seseorang yang berpengetahuan baik dapat lebih memelihara tingkat kesehatannya dari pada seseorang yang berpengetahuan kurang.

\section{Hubungan Pendidikan dengan Pemberian Vitamin A pada Balita (6-59) Bulan}

Seseorang yang memiliki pendidikan tinggi cenderung untuk mendapatkan informasi baik dari orang lain maupun dari media massa, sebaliknya tingkat pendidikan yang kurang akan menghambat perkembangan dan sikap seseorang terhadap nilai-nilai yang baru diperkenalkan (Nursalam, 2008).

Ketidaktahuan dapat disebabkan karena pendidikan yang rendah, seseorang dengan tingkat pendidikan terlalu rendah akan sulit menerima pesan, mencerna pesan dan informasi yang disampaikan sehingga pengetahuan tentang pemberian Vitamin $A$ terbatas (Amanati, 2016).

Hasil penelitian ini sejalan dengan penelitian yang dilakukan oleh Fatmawati, dkk (2010) dengan judul "Hubungan Tingkat Pengetahuan dan Pendidikan Ibu dengan Kunjungan Balita di Posyandu pada Bulan Vitamin A di Desa Katonsari Kecamatan Demak Kabupaten Demak" yang menyebutkan bahwa pendidikan orang tua merupakan salah satu faktor yang penting dalam tumbuh kembang anak, karena dengan pendidikan yang baik, maka orang tua dapat menerima segala informasi dari luar terutama tentang cara pengasuhan anak yang baik dan bagaimana cara menjaga kesehatan anaknya.

\section{Hubungan Pekerjaan dengan Pemberian Vitamin A pada Balita (6-59) Bulan}

Faktor pekerjaan berpengaruh pada peran ibu yang memiliki bayilanak balita seperti timbulnya suatu masalah pada ketidakaktifan ibu berkunjung ke Posyandu, karena mereka mencari nafkah untuk memenuhi kebutuhan yang belum cukup, sehingga berdampak pada tidak adanya waktu para ibu untuk membawa anak mereka ke Posyandu untuk mendapatkan Vitamin A karena kesibukan mereka dalam bekerja (Amanati, 2016).

Kelompok responden dengan jenis pekerjaan ibu rumah tanggalah yang lebih dominan mengunjungi Posyandu untuk mendapatkan Vitamin A dari pada yang berkegiatan atau bekerja di luar rumah. Sedangkan kelompok responden PNS dan pegawai swasta pada umumnya terikat pada jam kerja instansi atau perusahaan tempat mereka bekerja, sehingga sulit menyesuaikan dengan jadwal Posyandu yang kegiatannya biasa dilakukan pada pagi hari yang bertepatan dengan hari kerja (Andryana, 2015).

Hasil penelitian ini sejalan dengan penelitian yang dilakukan oleh Daniel dan Sulistiawati (2017) dengan judul "Hubungan Pekerjaan Ibu dengan Kunjungan Balita ke Posyandu Kenanga I di Wilayah Kerja Puskesmas Loa Ipuh" menyebutkan bahwa ibu yang memiliki pekerjaan tidak memiliki banyak waktu untuk berkunjung ke Posyandu. Sebaliknya ibu yang tidak bekerja memiliki waktu lebih banyak untuk beristirahat dan meluangkan waktu untuk membawa anaknya ke Posyandu sehingga dapat mendapatkan Vitamin A.

\section{KESIMPULAN DAN SARAN}

Faktor pengetahuan, pendidikan dan pekerjaan mempunyai hubungan yang signifikan dengan pemberian Vitamin A pada balita (6-59) bulan di Wilayah Kerja Puskesmas Kandai Kota Kendari.

Bagi para ibu diharapkan untuk meningkatkan pengetahuan dan kesadaran akan upaya pemberian Vitamin A pada balita, serta aktif menggali informasi mengenai kebutuhan balita dalam masa pertumbuhan sehingga tumbuh kembang anak akan semakin optimal karena kebutuhan balita akan Vitamin A dapat tercukupi. Selain itu, bagi para ibu yang bekerja diharapkan dapat meluangkan waktunya untuk membawa anaknya ke Posyandu, hal tersebut dapat dilakukan dengan meminta izin di tempat ibu bekerja atau 
bertukar jadwal ketika waktu penyelenggaraan kegiatan Posyandu. Apabila hal tersebut tidak memungkinkan, ibu dapat meminta bantuan kepada keluarga untuk membawa anaknya ke Posyandu sehingga kebutuhan terhadap Vitamin A tetap terpenuhi.

\section{REFERENSI}

Almatsier, S (2010). Buku Prinsip Dasar IImu Gizi Cetakan Kesembilam. Jakarta : PT Gramedia Pustaka Utama

Amanati, DW dkk (2016). Korelasi Pendidikan dan Pekerjaan Ibu dengan Keaktifan Balita ke Posyandu di Desa Gandu Kecamatan Mlarak Kabupaten Ponorogo. Jurnal Akbid Harapan Mulya Ponorogo

Andryana, R (2015). Minat Ibu Mengunjungi Posyandu di Wilayah Kerja Puskesmas Simpang Baru Kecamatan Tampan. Jom FISIP Vol. 2 No.2 Oktober 2015

Bart (2009). Psikologi Kesehatan. Jakarta : PT. Gramedia Widiasa Indonesia

Cahyaningrum, F (2017). Hubungan Tingkat Pengetahuan Ibu tentang Vitamin A dengan Kepatuhan Memberikan Kapsul Vitamin A pada Balita Usia 12-59 Bulan di Wilayah Kerja Puskesmas Rowosari Kota Semarang. Maternal, Vol II, No.1 April 2017

Daniel \& Sulistiawati (2017). Hubungan Pekerjaan Ibu dengan Kunjungan Balita ke Posyandu Kenanga I di Wilayah Kerja Puskesmas Loa Ipuh. Jurnal Kebidanan Mutiara Mahakam. Vol V, No. 2 September 2017

Dinkes Sultra (2017). Profil Kesehatan Sulawesi Tenggara. Kendari : Dinas Kesehatan Provinsi Sulawesi Tenggara.

Fatmawati, E dkk (2010). Hubungan Tingkat Pengetahuan dan Pendidikan Ibu dengan Kunjungan Balita di Posyandu pada Bulan Vitamin A di Desa Katonsari Kecamatan
Demak Kabupaten Demak. Jurnal Universitas Muhammadiyah Semarang

Kemenkes RI (2016). Petunjuk Teknis Pelaksanaan Bulan Kapsul Vitamin A Terintegrasi Program Kecacingan dan Crash Program Campak. Jakarta : Kementerian Kesehatan Republik Indonesia

Nursalam (2008). Konsep dan Penerapan Metodologi Penelitian IImu Keperawatan. Jakarta : Salemba Medika

Puskesmas Kandai (2018). Profil Puskesmas Kandai. Kendari 